\title{
Smart City Innovation within the Sharing Economy: Urban Innovation and Collaborative Consumption
}

\author{
Marta Christina SUCIU \\ Bucharest University of Economic Studies, Bucharest, Romania \\ christina.suciu@economie.ase.ro \\ Diana-Florentina NASULEA \\ Bucharest University of Economic Studies, Bucharest, Romania \\ diana@nasulea.ro \\ Christian NASULEA \\ University of Bucharest, Bucharest, Romania \\ christian@nasulea.ro
}

\begin{abstract}
With the increase of population and the increasing expectations of said population, urban environments require modern solutions for old and new problems alike. Technological and institutional innovation have both alleviated or solved many of the problems of modern cities. When we speak of smart cities, we tend to imagine solutions that focus on big data and its potential to help direct policy in a topdown approach whereas the sharing economy evokes bottom-up solutions where groups of people get together to solve community issues. Modern cities face a large number of challenges ranging from housing to air quality, to education, healthcare and emergency services or parking and traffic management. The list is virtually endless. They do, however, also present certain advantages over smaller, spread-out communities as having large numbers of people in a relatively small geographical space allows for innovative resource sharing solutions that would not be possible or might not be efficient otherwise. In a sense, population density is one of the biggest challenges of modern cities but also one of their greatest opportunities. We set out to analyse current and potential intersections between smart city technologies and solutions arising from the sharing economy. We look at existing smart city technology and the potential to expand its applications by giving more control to the citizens themselves and we examine a mathematical model that assess the viability of sharing cities. If we desire our future cities to be human-friendly, ecofriendly and sustainable it's important to understand which solutions have the greatest potential to lead us down the path of sustainability.
\end{abstract}

Keywords: smart cities, sharing economy, big data, sustainability, innovation, technology.

\section{Introduction}

In 2019, 54\% of the worldwide population lived in cities (PRB, 2019). In Europe, the degree of urbanization has reached 74\%. Projections show that the next 30 years will bring another 2.5 billion people to cities (UN, 2018). From small cities to mega cities, urban growth is posing challenges in matters of transportation, housing, energy systems but also employment, education, healthcare and many other infrastructures. A general trend of making cities inclusive and sustainable encourages a series of new business models to develop, blurring the boundaries between providers and consumers, whose idle capacities become a source of income and respectively, a means to an end.

In most big cities, sharing is no longer a matter of novelty. Car sharing, bike sharing, and house sharing are only a few of the activities that today are part of our routines of commuting, traveling or simply existing in the urban jungles. But they came to be because of the high scale development of communication technologies, GPS, and, of course, the Internet. While the 
innovative new platforms soon became the focus of many scholars, there's still room for developing and exploring a deeper understanding of how these platforms have changed the urban landscape, the social experience of living in cities and even interactions between people. Sharing became the attribute of an urban space whose needs and resources became increasingly large and its implications are still far from being completely understood (Davidson \& Infranca, 2016).

While we continue to talk about new innovative sharing platforms, the sharing economy is

PICBE $\mid 1148$ already 10 years old. A lot of research has been undertaken by scholars, organizations but also private companies trying to unlock it, to explain it and to assess its potential. More recently, the sharing economy is being studied as a complementary field of the smart city concept. This happens mostly because both ideas reveal innovations led by consumers' needs whose aim of sharing resources, skills, time and data is made possible through information and communications technology (ITC) (Gori et al., 2015).

The European Commission (2020) defines smart cities as ' a place where traditional networks and services are made more efficient with the use of digital and telecommunication technologies for the benefit of its inhabitants and business. `. The sharing economy on the other hand lacks a consensus on its definition because it is often interpreted through a wide array of concepts such as digital economy, gig economy, platform economy, peer economy, collaborative consumption, crowd economy and many others. However, most definitions include ITC as a means of facilitating the exchange, as explained by Curtis and Lehner (2019). Both the sharing economy and smart cities use technology to increase efficiencies, enhance quality of life and reduce costs. However, the sustainability and viability of these resources is often contested. While some scholars have praised the positive social impact of the sharing economy in the urban space that fosters social trust and collaboration (Botsman \& Rogers, 2011), but also a use of idle capacity which positively benefits the environment due to lower levels of used energy and waste (Belk, 2010), others believe the sharing economy to be nothing more than an ITC based business model that takes advantage of regulatory grey areas when it comes to unorthodox labour practices or for profit activities undertaken by companies rather than peers ${ }^{1}$ (Frenken, Meelen, Arets, \& Van de Glind, 2015) (Frenken et al.; Kallis, 2013).

The new technologies of smart sharing cities have truly changed the way people today perceive access to different resources but also the urban lifestyle in cities across the globe. From the urban landscape to big industries like tourism, transportation, food and retail, the new business models have not only created financial opportunities for millions of workers but they have also challenged traditional companies and institutions alike, making them adapt their behaviour and allowing for consumer-led initiatives to develop a more sustainable entrepreneurial culture.

Following the research on smart cities as key drivers of the sharing economy, our paper describes a mathematical model designed to assess the viability of the sharing economy business models under different scenarios, based on the motivation of involved parties and additional externalities. Private and public investments with or without nudging are discussed as part of the model.

\footnotetext{
${ }^{1}$ Kallis (2013) considers that a company such as Airbnb should not be considered part of the sharing economy but a capitalist corporation since most transactions are pure rental based on money. Following the same idea, Pick (2015) argues that Uber is not part of the sharing economy because many Uber cars are on the road because of the app and not to make use of the idle capacity, as the sharing economy literature suggests as main characteristic. Similarly, Frenken et al. (2015) argue that the issue lies in the substantial differences between C2C, B2C models which they consider more like product-service economy and not necessarily peer-to-peer due to the character of the providers.
} 


\section{Literature Review}

McLaren \& Agyeman's (2015) book on Sharing Cities is probably the most thorough applied research on the theory of sharing within urban environments. The two authors explore the concept of sharing as the cornerstone of contemporary cities which aim to become sustainable and form a sharing culture that starts from the grassroots, a perspective which is also an idea shared by Sundararajan (2016). Their five case-studies on the cities of San Francisco, Seoul, Copenhagen, Medellin and Amsterdam have become notorious for the innovative approach and success of the applied policies and sharing-based business-models. Applied research on the case of different cities has been extensively done also by Bernardi (2015) for the cases of Milan and Seoul, and Zvolska et al. (2019) who are focusing on the development of a conceptual framework that specifies the roles cities assume when governing urban sharing: city as regulator, city as provider, city as enabler and city as consumer. Salice and Pais (2017) are analysing the sharing economy as an urban phenomenon based on an elaboration of Polanyi's taxonomy model, using as case studies San Francisco, Amsterdam, Seoul and Milan. Their conclusions show that investments in infrastructure and digital service are the first means to stimulate the sharing economy, while the approach towards becoming sharing cities can be adapted to local culture and economic attributes, ranging from promoting private-sector models, to community-based business models or the development of social sharing programmes within the labour market. A study by Sharp (2018) uses the transformative social innovation theory to develop a comparative analysis of Shareable's ${ }^{2}$ Sharing Cities Network and Airbnb's Home Sharing Clubs, arguing for the grassroots mobilisation promoted by the first and the regulatory hacking used by the latter to influence urban policy.

Concerning the issue of the sharing economy's businesses transforming the urban environment, Davidson and Infranca (2016) argue that short-term rentals but also other platforms that lower the costs of entry can change both the aspect and the economics of neighbourhoods that attract travellers, which leads to a boom of restaurants, cafés and bars but can also make other businesses with physical presence disappear as they are substituted by peer-to-peer services. The key driver of the sharing economy in their example is the city, as it leverages proximity and density. Their research also explores examples in which the sharing economy leads to a change in the architecture of new buildings that become more appealing if they include micro-units for living or co-working, which afterwards leads to changes in social aspects, like in the case of sharing platforms building trust between strangers who would otherwise be wary of each other. Acquier et al. (2019) explore the different business configurations based on social, eocnomic, value creation and distribution mechanism with a focus on the implications for tha management of sharing initiatives, while Fraiberger and Sundararajan (2017) develop a dynamic model of a peer-to-peer rental market that incoporates transaction costs and a series of additional factors that influence the supply and demand for sharing goods.

On the impact of the sharing economy on 'incumbents' (established companies), Ciulli and Kolk (2019) explore the implications for environmental, social and economic value creation of the different ways in which incumbents change and adapt their business models to join the sharing economy. Their conclusions draw on sustainability-related issues for the respective types of sharing-approaches.

\footnotetext{
${ }^{2}$ Shareable is the largest news site for the sharing economy, founded by Neal Gorenflo in 2009 to promote sharing economy business-models and initiatives that have the potential to restore community life, distribute power relations and create social impact
} 


\section{Model and Discussion}

Cities are a natural habitat for the sharing economy and collaborative consumption due to population density and urban living (Sundararajan, 2016). Online platforms and integrated systems are only functional if they are based on proximity, short distances and local communities. Sharing makes sense only if it is convenient and efficient in terms of time. One can share food, a car or a bike only if you are in the same place or somewhere close by. If distance is a problem, then people would more likely chose owning over sharing. This partly explains why the first initiatives which launched the sharing economy were ride-sharing platforms.

Collaborative consumption and the sharing economy also constitute potential instruments that cities can use to become smart. The general approach towards innovation and collaborative platforms shows the complementarity between the two concepts. Smart cities mean to engage on one side the community and the local administration, and on the other side a series of services that use smart technologies (Gori et al., 2015).Sharing platforms are also about matching consumers with providers in their proximity. In the end, the aim of sharing smart cities is to find solutions for urban communities that lead to economic, social and environmentally friendly developments.

A study undertaken by the European Commission (2018) estimated the overall size of the collaborative economy for EU-28 in 2016 at 26.5 billion euros, with the largest revenues coming from the finance sector (EUR 9,6 billion), followed by accommodation (EUR 7,3 billion), online skills (EUR 5,6 billion) and transport (EUR 4 billion). According to the study, in 2016 there were about 651 for-profit sharing platforms across the European Union, with high levels of activity especially in France, UK, Germany, Spain and Italy. Most of these platforms were based in urban centres, especially in bigger cities with high population density, traffic and incoming tourists. Table 4.1 shows a classification of the sharing economy platforms available in European cities. If transportation, finance, and accommodation are already popular and used on a large-scale, new platforms keep developing also in other sectors such as education, with more and more peer-topeer initiatives becoming widely available, utilities, health, food and general goods.

Table 1 Key Sectors in the Sharing Economy

\begin{tabular}{|c|c|c|c|}
\hline Sector & Type of Platform & Sector & Type of Platform \\
\hline \multirow[t]{4}{*}{ Transportation } & Ride Sharing & \multirow[t]{3}{*}{ Finance } & Money Lending \\
\hline & Ride Sourcing & & Crowdfunding \\
\hline & Ride Splitting & & Insurance \\
\hline & Vehicle Splitting & Food & Meals \\
\hline \multirow[t]{4}{*}{ Space } & Accommodation & \multirow[t]{2}{*}{ General Goods } & Unused/Used Products \\
\hline & Work Space & & Loaner Products \\
\hline & Parking space & \multirow{2}{*}{ Learning } & $P 2 P$ Learning \\
\hline & Recreational Space & & Open Courses \\
\hline \multirow[t]{3}{*}{ Utilities } & Telecommunications & \multirow[t]{2}{*}{ Skills } & Personal Services \\
\hline & Information & & Professional Services \\
\hline & Energy & Health & Medical Equipment/Service \\
\hline
\end{tabular}

Source: adapted from European Commission (2018), Ricart \& Berrone, (2017), World Economic Forum, PWC

While the sharing economy often implies only peer-to-peer models, most cities have adopted a variety of ways of sharing. Table 4.2 shows a classification of the types of sharing according to the type of provider, business model, revenues, scalability, impact and motivation. 
Table 2 Models of sharing in EU cities

Centralized Decentralized

Composite

Institutional

B $\quad$ B2B/B2C P2P $\quad$ Hybrid $\quad$ Public Sector

PICBE | 1151

Business $\quad$ Consumer $\quad$ Business \& Consumer Public/Institutional

\begin{tabular}{ccccc}
\hline Business & Consumer & $\begin{array}{c}\text { The business sets } \\
\text { certain standards and } \\
\text { consumers can also } \\
\text { specify terms }\end{array}$ & $\begin{array}{c}\text { Local governing } \\
\text { authorities }\end{array}$ \\
\hline Business/Asset Owner & $\begin{array}{c}\text { Mostly the individual } \\
\text { provider with a } \\
\text { commission-based fee } \\
\text { going to the platform }\end{array}$ & $\begin{array}{c}\text { Mostly the individual } \\
\text { provider with a } \\
\text { commission-based fee } \\
\text { going to the platform }\end{array}$ & Local budget \\
\hline on the level of use & $\begin{array}{c}\text { Easy if the consumer } \\
\text { base increases }\end{array}$ & $\begin{array}{c}\text { Moderate, with control } \\
\text { over pricing and } \\
\text { revenues }\end{array}$ & $\begin{array}{c}\text { Depends on popularity } \\
\text { and investment }- \text { can } \\
\text { be scaled to other big } \\
\text { cities at national level }\end{array}$ \\
\hline
\end{tabular}

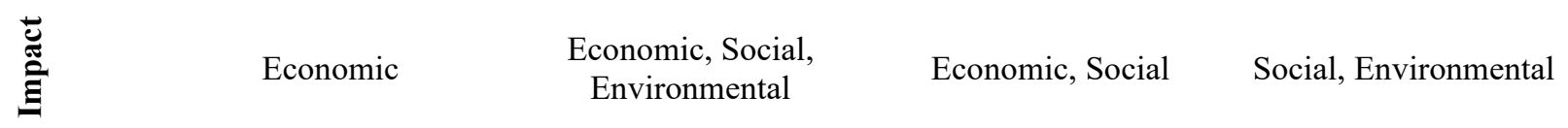

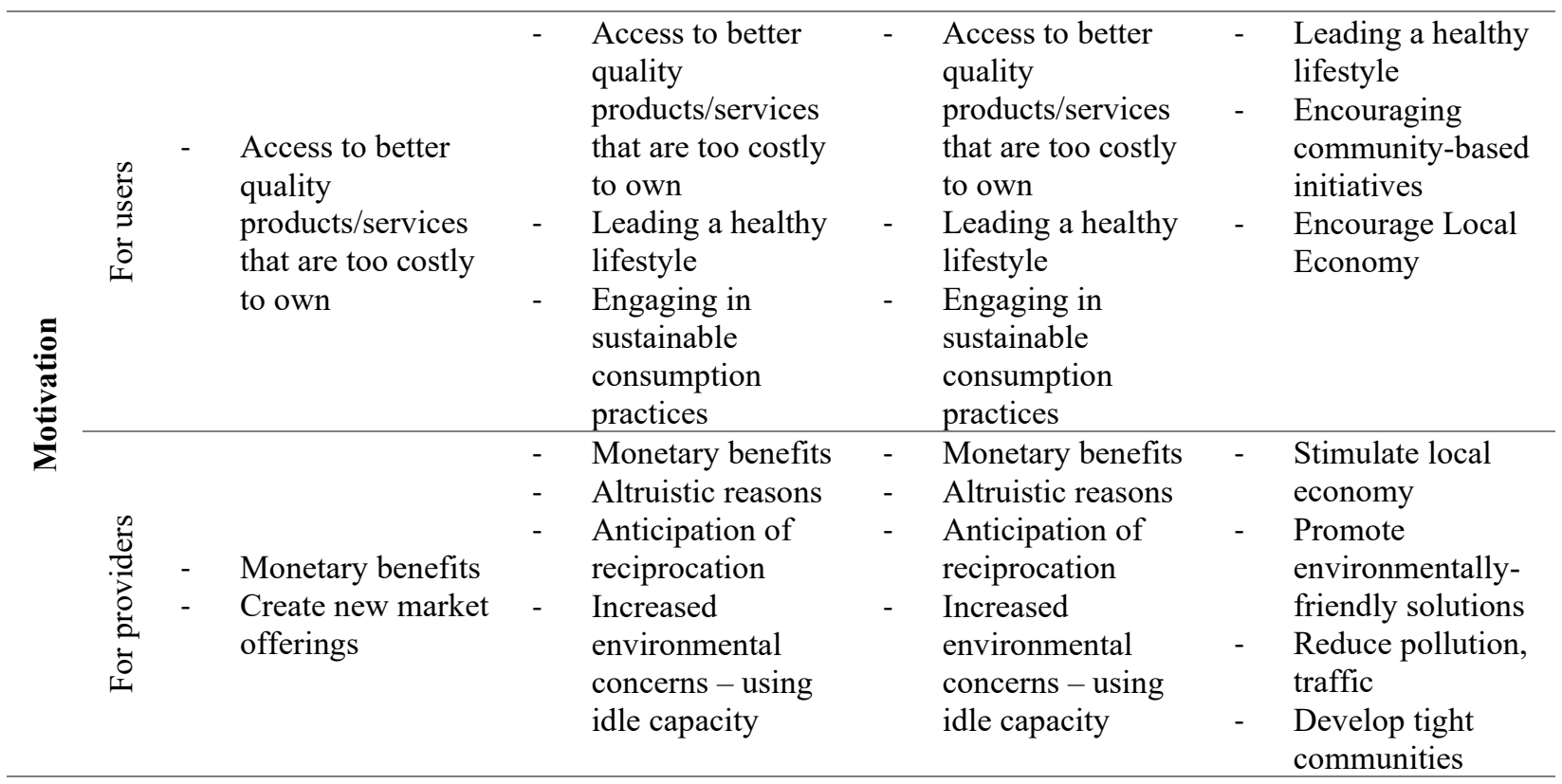




$$
\begin{aligned}
& \text { Etsy, Ebay, } \\
& \text { BlaBlaCar, } \\
& \text { Turo, Lime } \\
& \text { Airbnb, } \\
& \text { Le Bon Coin, } \\
& \text { KissKissBankBank } \\
& \text {, HomeGrown } \\
& \text { Exchange }
\end{aligned}
$$

Source: adapted after World Economic Forum, PWC (2017).

Although centralized models are often disregarded by the sharing economy debate, new companies that allow businesses to rent machinery to one another or make use of trucks collaboratively are promoting a more sustainable growth model, in which resources are being wasted less. However, for the case of smart sharing cities, the models we are most interested in, due to their impact on the urban environment, are decentralised, P2P, composite - hybrid models or institutional initiatives of local administrations meant to encourage the aforementioned P2P, hybrid models, when these are centred on individual users who become the main beneficiaries of both revenues and the goods/services being provided.

Often, investment in smart city technologies or adjustments in legal frameworks, designed to encourage the development of certain models related to the sharing economy, are undertaken experimentally, based mostly on approximate information from public opinion, rather than hard facts or a clear model designed to assess the benefits of those investments or changes. This happens both in cases in which the investor is a private company and in cases in which a public entity is the initial investor. The diversity of activities encountered within the sharing economy might make it seem like a unified assessment model is impossible to develop. In spite of this, we set out to find those common points that can be used to develop a single assessment model that can be used as a starting point for any cost-benefit analysis related to smart sharing cities.

Mathematical modelling was used to assess the impact of population density on the viability of sharing economy business models. A deconstructive approach was used in modelling prospective variables to be included in a socio-economic model designed to be generic enough to be applicable and appropriate to all sharing economy models identified in our research.

Based on the findings above we selected population density and cost savings as the starting point for our first model. The standard form of a cost-benefit analysis is:

$$
\frac{\text { Benefit }}{\text { Cost }}=\frac{\sum \text { Present Value of Future Benefits }}{\sum \text { Present Value of Future Costs }}
$$

Where $\frac{\text { Benefit }}{\text { Cost }}$ must be $>1$ for any activity that is worth undertaking.

Population density factors into the math through cost, the greater the distance between agents involved into a sharing economy interaction the greater the transportation cost. Transportation Costs can be expressed as the product of Cost per Distance Unit (C/DU) and the number of distance units (D), as a factor of Total Cost or, as noted above, Future Costs (FC). We will simply account for all other costs related to these interactions by referring to them as Other Costs (OC). It is important to note that Future Costs refer to all the costs incurred by an individual 
or entity during a single transaction and the sum of future costs is the sum of costs for all transactions.

$$
\begin{gathered}
F C=O C+C / D U \times D \\
\frac{\text { Benefit }}{\text { Cost }}=\frac{\sum \text { Present Value of Future Benefits }}{\sum \text { Present Value }\left(O C+\frac{C}{D U} \times D\right)}
\end{gathered}
$$

PICBE $\mid 1153$

From the point of view of public administrators attempting to boost positive social outcomes, or from the point of view of what is desirable for society as a whole, it makes more sense to discuss average benefits and average costs:

$$
\mu \frac{\text { Benefit }}{C o s t}=\frac{P V(\mu \text { Future Benefits })}{P V\left[\mu\left(O C+\frac{C}{D U} \times \mu D\right)\right]}
$$

In this form we can replace average distance with a derivative of population density $\left(\rho_{P}\right)$.

$$
\rho_{P}=\frac{P}{D U} \quad \mu D=\frac{D U}{P}
$$

Therefore:

$$
\mu \frac{\text { Benefit }}{\operatorname{Cost}}=\frac{P V(\mu \text { Future Benefits })}{P V\left[\mu\left(O C+\frac{C}{D U} \times \frac{1}{\rho_{P}}\right)\right]}
$$

On the benefit side of the computation we have to deal with two types of benefits: direct benefits, going to the individual or the entity, and positive externalities $\left(E X^{+}\right)$.

$$
\mu \frac{\text { Benefit }}{\operatorname{Cost}}=\frac{P V\left[\mu\left(\text { Direct Benefits }+E X^{+}\right)\right]}{P V\left[\mu\left(O C+\frac{C}{D U} \times \frac{1}{\rho_{P}}\right)\right]}
$$

At the breakeven point of Benefit and Cost, where average Benefit over Cost equal 1, we can expect the Present Values of average Benefit to equal the Present values of average Other Costs + Transportation Cost over Distance Unit times Population Density as shown below:

$$
P V\left[\mu\left(\text { Direct Benefits }+E X^{+}\right)\right]=P V\left[\mu\left(O C+\frac{C}{D U \times \rho_{P}}\right)\right]
$$

Present Value can be estimated using a standard Net Present Value function:

$$
\text { Net Present Value }=\text { Future Value } \times \frac{1}{(1+r)^{n}}
$$

Where $r$ is the discount rate and $n$ is the number of years. 
Due to the fact that the number of years required for the Future Value of both Costs and Benefits to manifest themselves may be different we ought to keep the $P V$ function embedded in the model, with the understanding that $P V$ in the model is an abbreviated form of $P V_{r, n}(x)$.

In Table 4.2 Direct Benefits from the sharing economy fall under economic impact, as they are usually monetary or qualitative. Either the individual or entity earns money, spends less money, or has access to more quality per monetary unit. To avoid overcomplicating the model we have decided to list social and environmental impact solely under positive externalities. We will refer to "earning money" as Income (I), "spending less money" as Savings (S), and "access to more quality pe monetary unit" Quality Variation $(\Delta \mathrm{Q})$.

$$
P V\left[\mu\left(I+S+\Delta Q+E X^{+}\right)\right]=P V\left[\mu\left(O C+\frac{C}{D U \times \rho_{P}}\right)\right]
$$

Going further, in a subsequent version of our model we decided to break down Other Costs into a more explicit list containing Individual Costs (C), Platform Costs (Cp), and Negative Externalities $\left(E X^{-}\right)$. On the left hand side we similarly decided to distinguish between Income (I) earned by asset owners involved in the sharing economy and Income (Ip) earned by sharing economy platform providers.

$$
P V\left[\mu\left(I+I p+S+\Delta Q+E X^{+}\right)\right]=P V\left[\mu\left(C+C p+E X^{-}+\frac{C}{D U \times \rho_{P}}\right)\right]
$$

A very simple observation we can make by looking at this form is that there is a very clear factor correspondence between some of the elements, like Individual Income (I) and Individual Cost (C), like Platform Income (Ip) and Platform Cost (Cp), like Positive Externalities $\left(E X^{+}\right)$and Negative Externalities $\left(E X^{-}\right)$. Not the same can be said of Improvements in Quality $(\Delta Q)$ which stand out as a separate source of individual benefit.

Another source of individual benefit, that is even harder to quantify than Improvements in Quality, are the motivational factors listed in Table 4.2, for both users and providers, under "altruistic reasons", or concerns about "sustainable consumption", or "using spare capacity". These sources of motivation lead to the appearance of a subjective benefit to the individual that is difficult to quantify but that is often strong enough to tip the scale. Subjective motivation has already been amply described in (Martin, 2016) and (Geissinger et al., 2018). We included benefits stemming from subjective Motivation (M) in our model on the benefit side.

To conclude preparations for our model analysis we need to add a variable for institutional intervention or nudging $(\mathrm{X})$ meant to definitively tip the scales in favor of implementing a new sharing economy model. This variable needs to be divided by Population (P), thus, our model becomes:

$$
P V\left[\mu\left(M+I+I p+S+\Delta Q+E X^{+}\right)\right]+\frac{X}{P}=P V\left[\mu\left(C+C p+E X^{-}+\frac{C}{D U \times \rho_{P}}\right)\right]
$$


Assuming Present Value is equal to Future Value, assuming some variables offset each other, as mentioned previously, and assuming that our standard Distance Unit is $1 \mathrm{~km}$, allows us to look at a radically simplified version of this model. The offset variables are Income, Platform Income, Savings, Positive and Negative Externalities, Cost and Platform Cost.

$$
X=\left(\frac{C}{\rho_{P}}-M-\Delta Q\right) \times P
$$

PICBE $\mid 1155$

This oversimplified model shows that local governing authorities or other institutional entities need only look at the relation between transport cost and population density to start assessing the viability of a policy decision regarding a particular sharing economy model. The more subjective motivation or improved quality play a part the less nudging is required. If $\mathrm{X}$ is smaller than 0 no nudging is required. Of course, in the interest of increased accuracy, the rest of the offset variables need to be factored back in but, given the highly probabilistic nature of the data, they should be added back in gradually in order to verify the results of the model with a few of the variables, with many of the variables, and with all the variables factored in.

Due to the uneven distribution of population and population density within a city, the distance unit chosen for the analysis matters. If the distance unit we choose is the size of the entire city we run the risk of arriving at wildly erroneous conclusions. If the distance unit is $1 \mathrm{~km}$ the resulting data will be more realistic. If the distance unit is $100 \mathrm{~m}$ the data will be that much better. A city is a dynamic matrix with both producers and consumers distributed very unevenly. As recently shown by Ji et al. (2020) disproving Connes' embedding conjecture (Connes, 1974) submatrices should also be assessed using big data and smart city technologies in order to ensure the accuracy of our results. As the distinction between producer and consumer continues to blur, thanks in great part to the sharing economy, it becomes more and more difficult to predict patterns of movement of people, products, and services through our cities.

\section{Conclusion}

In the world of sharing economy business models there is a close relationship between viability and population density. Cities allow for a fast exchange of goods and services due to population density and proximity, with efficient high-quality matching of supply and demand and increased productivity. In this paper, we have developed a model for better understanding the viability of sharing models within cities.

Data on population density needs to be accounted for city-wide but using granular information. Average population density at the city level is not enough. Big data must be used in conjunction with smart city-specific technologies to ensure a model is viable before making any kind of decision to nudge, to make public policies, or to invest taxpayer money in any form of stimulus.

The participants in the sharing cities initiatives are diverse, and so are their motivations for participating. Given the structure of our assessment model for sharing economy businesses, it is quite likely that the best business plans for new sharing economy businesses will continue to be those which require no nudging or institutional intervention whatsoever. Local governments and institutional entities will most often arrive at the conclusion that the best thing to do is to stay out of the way if they run the correct decision-making analyses. 
Citizens should be encouraged by the smart cities they inhabit to contribute data to both public and private platforms that can make those smart cities smarter still. That data is needed for centrally coordinated systems and for future sharing economy platforms and models.

\section{References}

Acquier, A., Carbone, V., \& Massé, D. (2019). How to Create Value(s) in the Sharing Economy: Business Models, Scalability, and Sustainability. Technology Innovation Management Review, 9(2), 5-24.

Belk, R. (2010). Sharing. Journal of Consumer Culture, 36, 71-735.

Bernardi, M. (2015). Sharing Cities. Governance Models and Collaborative Practices in the Urban Contexts. Università degli Studi di Milano-Bicocca Dipartimento di Sociologia e Ricerca Sociale. Dottorato di Ricerca in Società dell'Informazione (Qua_si).Retrieved from https://boa.unimib.it/retrieve/handle/10281/96087/140916/phd_unimib_039475.pdf.

Botsman, R., \& Rogers, R. (2011). What's mine is yours: How collaborative consumption is changing the way we live. London: Collins.

Ciulli, F., \& Kolk, A. (2019). Incumbents and business model innovation for the sharing economy: Implications for sustainability. Journal of Cleaner Production, 214, 995-1010.

Connes, A. (1974). Caractérisation des espaces vectoriels ordonnés sous-jacents aux algèbres de von Neumann. Annales de l'institut Fourier, 121-155.

Curtis, S. K., \& Lehner, M. (2019). Defining the Sharing Economy for Sustainability. Sustainability, 11(3).

Curtis, S., \& Lehner, M. (2019). Defining the Sharing Economy for Sustainability. Sustainability, $11(3), 567$.

Davidson, N. M., \& Infranca, J. J. (2016). The Sharing Economy as an Urban Phenomenon. Yale Law \& Policy Review, 34, 215-279.

European Commission (2018). Study to Monitor the Economic Development of the Collaborative Economy in the EU. Brussels: European Commission.

European Commission (2020). Smart Cities. Retrieved from https://ec.europa.eu/info/eu-regionaland-urban-development/topics/cities-and-urban-development/city-initiatives/smartcities_en.

Fraiberger, S., \& Sundararajan, A. (2017). Peer-to-Peer Rental Markets in the Sharing Economy. NYU Stern School of Business Research Paper (First version March 2015; current version September 2017), 0-39. Retrieved from https://papers.ssrn.com/sol3/papers.cfm?abstract_id=2574337.

Frenken, K., Meelen, T., Arets, M., \& Van de Glind, P. (2015). Smarter regulation for the sharing economy. The Guardian. Retrieved from http://www.theguardian.com/science/politicalscience/2015/may/20/smarter-regulation-for-the-sharing-economy.

Geissinger, A., Laurell, C., Oberg, C., \& Sandstorm, C. (2018). How sustainable is the sharing economy? On the sustainability connotations of sharing economy platforms. Journal of Cleaner Production, 206, 419-429.

Gori, P., Parcu, P. L., \& Stasi, M. L. (2015). Smart Cities and Sharing Economy. European University Institute - Robert Schuman Centre for Advanced Studies. Retrieved from http://cadmus.eui.eu/bitstream/handle/1814/38264/RSCAS_2015_96.pdf?sequence=1.

Ji, Z., Natarajan, A., Vidick, T., Wright, J., \& Yuen, H. (2020). MIP ${ }^{*}=R E$. Retrieved from https://arxiv.org/abs/2001.04383. 
Kallis, G. (2013). AirBnb is a rental economy, not a sharing economy. The Press Project. Retrieved from http://www.thepressproject.net/article/68073/AirBnb-is-a-rental-economy-not-asharing-economy.

Martin, C. J. (2016). The sharing economy: A pathway to sustainability or a nightmarish formof neoliberal capitalism?. Ecological Economics, 121, 149-159.

McLaren, D., \& Agyeman, J. (2015). Sharing Cities: A Case for Truly Smart and Sustainable

PICBE | 1157 Cities. MIT press.

Pick, F. (2015). Sustaining hierarchy - Uber isn't sharing. Retrieved from https://www.ouishare.net/article/sustaining-hierarchy-uber-isnt-sharing.

PRB (2019). Population Reference Bureau. Statista. Retrieved from https://www.statista.com/statistics/270860/urbanization-by-continent/.

Ricart, E. J., \& Berrone, P. (2017). The Collaborative Economy in Cities. Harvard Business Review, 265, 52-63.

Salice, S. M., \& Pais, I. (2017). Sharing Economy as an Urban Phenomenon: Examining Policies for Sharing Cities. Policy Implications of Virtual Work, 199-228.

Sharp, D. (2018). Sharing Cities for Urban Transformation: Narrative, Policy and Practice. Urban Policy and Research, 36(4), 1-14.

Sundararajan, A. (2014). Peer-to-Peer Businesses and the Sharing (Collaborative) Economy: Overview, Economic Effects and Regulatory Issues. Written testimony for the hearing titled, The Power of Connection: Peer-to-Peer Businesses, held by the Committee on Small Business of theUnited States House of Representatives, January 15th, 2014. Retrieved from https://republicans-smallbusiness.house.gov/uploadedfiles/1-152014_revised_sundararajan_testimony.pdf.

Sundararajan, A. (2016). The sharing economy: The end of employment and the rise of crowdbased capitalism. Mit Press.

UN (2018). 68\% of the world population projected to live in urban areas by 2050, says UN. United Nations- Department of Economic and Social Affairs. Retrieved from https://www.un.org/development/desa/en/news/population/2018-revision-of-worldurbanization-prospects.html.

World Economic Forum, PWC. (2017). Collaboration in Cities: From Sharing to "Sharing Economy". $\quad$ Retrieved from http://www3.weforum.org/docs/White_Paper_Collaboration_in_Cities_report_2017.pdf.

Zvolska, L., Lehner, M., Palgan, Y. V., Mont, O., \& Plepys, A. (2019). Urban sharing in smart cities: the cases of Berlin and London. The International Journal of Justice and Sustainability, 24(7), 1-18. 